\title{
Implementasi Program Kesejahteraan Masyarakat Kelurahan Melalui Wadah Kampung Keluarga Berencana Di Kelurahan Tampuna Kecamatan Bungi Kota Baubau
}

\author{
Wa Ode Wati Nurbaena ${ }^{1}$ \\ ${ }^{1}$ BKKBN Propinsi Sulawesi Tenggara \\ Email:watinurbaena74@gmail.com
}

\begin{abstract}
Abstrak, Penelitian ini bertujuan untuk mendeskipsikan dan menganalisa bagaimana Implementasi Program Kesehjateraan Masyarakat Kelurahan Melalui Kampung Keluarga Berencana di Kelurahan Tampuna Kecamatan Bungi Kota Baubau. Penelitian yang digunakan adalah penelitian Deskriptif Kualitatif. Teknik Analisis Data menggunakan metode deskriptif kualitatif. Hasil penelitian menjelaskan bahwa implementasi program kampung $\mathrm{KB}$, dapat dijelaskan dalam empat indikator yang dinilai sudah berjalan dengan optimal. Hanya saja faktor sumberdaya manusia dan sarana prasarana yang masih kurang optimal, selain itu budaya masyarakat secara umum juga menjadi tantangan tersendiri bagi program kampung KB dari sisi program kependudukan.
\end{abstract}

Kata Kunci : Implementasi, Kampung KB, Kesejahteraan Masyarakat

Abstract, This study aims to describe and analyze how the implementation of the Village Community Health Program through the Family Planning Village in the Tampuna Village, Bungi District, Baubau City. The research used is descriptive qualitative research. The data analysis technique used a qualitative descriptive method. The results of the study explain that the implementation of the village family planning program can be explained in four indicators which are considered to be running optimally. It's just that the human resource factor and infrastructure are still less than optimal, besides that the culture of the community in general is also a challenge for the KB village program in terms of the population program.

Keywords: Policy Implementation, KB Village, Community Welfare 


\section{Pendahuluan}

Program Kampung Keluarga Berencana (Kampung KB) adalah merupakan Program Prioritas dan unggulan yang yang bertujuan untuk meningkatkan taraf hidup masyarakat menjadi keluarga berkualitas. Diatur dalam Undang-undang Nomor 52 Tahun 2009, tentang Perkembangan Kependudukan dan Pembangunan Keluarga sebagai dasar pelaksanaan Program Kependudukan dan Keluarga Berencana menekankan kewenangan Badan Kependudukan dan Keluarga Berencana (BKKBN) tidak hanya terbatas pada masalah Pembangunan Keluarga Berencana dan Keluarga Sejahtera saja namun juga menyangkut masalah pengendalian penduduk.

Sejalan dengan arah kebijakan pembangunan nasional pemerintah tahun 2015-2019, BKKBN diberi mandat untuk mensukseskan Agenda Pembangunan Nasional (Nawacita), khususnya Agenda Prioritas ke-3 “Membangun Indonesia dari Pinggiran dengan Memperkuat Daerahdaerah dan Desa dalam rangka Negara Kesatuan", Agenda Prioritas ke-5 “ Meningkatkan Kualitas Hidup Manusia Indonesia", serta Agenda Prioritas ke-8 "Revolusi Karakter Bangsa" melalui Pembangunan Kependudukan dan Keluarga Berencana. Amanat Presiden RI kepada BKKBN agar dapat menyusun suatu kegiatan atau program yang dapat memperkuat upaya pencapaian sasaran Pembangunan Bidang Pengendalian Penduduk dan Keluarga Berencana 20152019 (BKKBN, 2018 : 20).

Kampung KB merupakan satu diantara kegiatan prioritas yang sesuai dengan instruksi presiden RI, terutama sebagai bentuk investasi Program KB yang manfaatnya dapat secara langsung diterima masyarakat. Untuk itu segera dilakukan langkah koordinasi lintas sektor, terutama dalam integrasi kegiatan yang akan dilaksanakan di Kampung KB. Program KB tidak lagi hanya fokus pada upaya pengendalian jumlah penduduk, namun juga bagaimana melalui Program KKBPK (Kependudukan, Keluarga Berencana dan Pembangunan Keluarga) dapat meningkatkan tingkat kesejahteraan masyarakat, maka dari itu, KB dipandang masih dibutuhkan untuk memenangkan persaingan global.

Kampung KB merupakan salah satu bentuk atau model miniatur pelaksanaan total Program KKBPK secara utuh yang melibatkan seluruh bidang di lingkungan BKKBN dan bersinergi dengan Kementerian atau Lembaga, mitra kerja, stakeholders instansi terkait sesuai dengan kebutuhan dan kondisi wilayah, serta dilaksanakan di tingkatan pemerintahan terendah (sesuai prasyarat penentuan lokasi kampung KB) di seluruh kabupaten dan kota. Kampung KB dikelola dan diselenggarakan oleh masyarakat dalam memberdayakan dan memberikan kemudahan kepada masyarakat untuk memperoleh pelayanan total program $\mathrm{KB}$, sebagai upaya mewujudkan keluarga yang berkualitas.

Setelah Kampung KB diluncurkan oleh BKKBN pada tahun 2016 sebagai miniatur pelaksanaan total program Kependudukan, Keluarga Berencana dan Pembangunan Keluarga (KKBPK) di tingkat 
pedukuhan yang melibatkan lintas sektor dan segenap komponen masyarakat, maka di tahun 2017, BKKBN kembali meluncurkan Rumah Data kependudukan yang berfungsi sebagai basis data dan informasi serta pusat intervensi pembangunan di tingkat mikro wilayah Kampung KB. Rumah Data Kependudukan yang kemudian dikenalkan pada masyarakat luas sebagai "Rumah Dataku" tersebut dipastikan memiliki urgensi dan manfaat yang sangat besar bagi masyarakat di lokasi Kampung KB yang dibentuk di setiap Kabupaten pada tahun 2016 dan setiap Kecamatan pada tahun 2017

Kesejahteraan menurut Badan Pusat Statistik (2017) adalah suatu kondisi dimana seluruh kebutuhan jasmani dan rohani dari rumah tangga tersebut dapat dipenuhi sesuai dengan tingkat hidup. Status kesejahteraan dapat diukur berdasarkan proporsi pengeluaran rumah tangga. Rumah tangga dapat dikategorikan sejahtera apabila proporsi pengeluaran untuk kebutuhan pokok sebanding atau lebih rendah dari proporsi pengeluaran untuk kebutuhan bukan pokok. Sebaliknya rumah tangga dengan proporsi pengeluaran untuk kebutuhan pokok lebih besar dibandingkan dengan pengeluaran untuk kebutuhan bukan pokok dan dapat dikategorikan sebagai rumah tangga dengan status kesejahteraan yang masih rendah.

Dalam Undang-Undang Republik Indonesia Nomor 52 tahun 2009, Keluarga Sejahtera adalah keluarga yang dibentuk berdasarkan atas perkawinan yang sah, mampu memenuhi kebutuhan hidup spiritual dan materiil yang layak, bertaqwa kepada Tuhan Yang Maha Esa, memiliki hubungan yang serasi, selaras dan seimbang antar anggota dan antar keluarga dengan masyarakat dan lingkungan (Undang-Undang Republik Indonesia Nomor 52 tahun 2009).

Kampung KB sebenarnya dirancang sebagai upaya membumikan, mengangkat kembali, merevitalisasi program KKBPK guna mendekatkan akses pelayanan kepada keluarga dan masyarakat dalam upaya mengaktualisasikan dan mengaplikasikan 8 (delapan) fungsi keluarga secara utuh dalam masyarakat. Dengan demikian kegiatan yang dilakukan pada Kampung KB tidak hanya identik dengan penggunaan dan pemasangan kontrasepsi, akan tetapi merupakan sebuah program pembangunan terpadu dan terintegrasi dengan berbagai program pembangunan lainnya.

Peningkatan ketahanan dan kesejahteraan keluarga dapat ditelusur melalui berbagi indikator yang merupakan pencerminan dari pelaksanaan delapan fungsi keluarga. Hal tersebut tercantum dalam Peraturan Pemerintah No.87 Tahun 2014 tentang Perkembangan Kependudukan dan Pembangunan Keluarga, Keluarga Berencana dan Sistem Informasi Keluarga. Dalam PP disebutkan delapan fungsi keluarga meliputi (1) fungsi keagamaan, (2) fungsi social budaya, (3) fungsi cinta kasih, (4) fungsi perlindungan, (5) fungsi reproduksi, (6) fungsi sosialisasi dan pendidikan, (7) fungsi ekonomi dan (8) fungsi pembinaan lingkungan.

Kampung KB ini dapat kita jadikan sebagai wahana pemberdayaan masyarakat melalui berbagai macam program yang mengarah pada upaya merubah sikap, prilaku dan cara berfikir (mindset) masyarakat kearah yang lebih baik, 
sehingga kampung yang tadinya tertinggal dan terbelakang dapat sejajar dengan kampung-kampung lainnya, masyarakat yang tadinya tidak memiliki kegiatan dapat bergabung dengan poktan-poktan yang ada, keluarga yang tadinya tidak memiliki usaha dapat bergabung menjadi anggota UPPKS yang ada.

Kampung KB adalah satuan wilayah setingkat RW, dusun atau setara, yang memiliki kriteria tertentu. Di dalamnya terdapat keterpaduan program kependudukan, Keluarga Berencana, pembangunan keluarga dan pembangunan sektor lainnya yang dilaksanakan secara terpadu. Kampung KB umumnya terbentuk di daerah yang ketimpangan sosialnya tinggi, seperti padat penduduk, keikutsertaan dalam program KB rendah, miskin, kumuh, dan ada balita stunting Namun sejauh ini integrasi program lintas sektor kementerian/lembaga terkait masih minim. Program-program yang dilaksanakan di Kampung KB masih didominasi oleh BKKBN, dan sebagiannya juga beririsan dengan penanggulangan masalah gizi kronis, yaitu stunting atau balita pendek

Kelurahan Tampuna Kecamatan Bungi ini adalah wilayah yang menjadi lokasi penelitian penulis karena wilayah ini terletak di Kota Baubau yang merupakan kota tempat tinggal penulis sehingga memudahkan akses penelitian di desa tersebut, selain itu juga Kelurahan Tampuna adalah Kelurahan yang baru dicanangkan dan masih dalam tahap proses pengimplentasian Program Kampung KB.

Penelitian in bertjuan untuk mengkaji sejumlah indikator dalam Implementasi Program Kesehjateraan Masyarakat
Kelurahan Melalui Wadah Kampung Keluarga Berencana Di Kelurahan Tampuna Kecamatan Bungi Kota Baubau, guna mengetahui apresiasi masyarakat di Kelurahan Tampuna Kecamatan Bungi Kota Baubau terkait Program Kampung KB.

\section{Metode Penelitian}

Dalam penelitian Implementasi Program Kesehjateraan Masyarakat Kelurahan Melalui Wadah Kampung Keluarga Berencana Di Kelurahan Tampuna Kecamatan Bungi Kota Baubau, jenis penelitian yang digunakan adalah Penelitian Deskriptif Kualitatif, hal ini dilakukan dengan cara pengamatan langsung dan wawancara terhadap informan yang ditentukan oleh penulis. Dari proses itu, data yang diperoleh dianalisis dengan kaidah Kualitatif (Sugiyono, 2009 : 39).

Selanjutnya pada analisis data tersebut berlangsung mengikuti kaidah penelitian kualitatif yakni secara interaktif, dimana pada setiap tahapan kegiatan tidak berjalan sendiri-sendiri. Meskipun tahap penelitian dilakukan sesuai dengan kegiatan yang direncanakan, akan tetapi kegiatan ini tetap harus dilakukan secara berulang antara kegiatan pengumpulan data, reduksi data, penyajian data serta verifikasi atau penarikan suatu kesimpulan.

\section{Hasil dan Pembahasan}

Penelitian ini menjelaskan perihal implementasi Program Kampung Keluarga Berencana dalam meningkatkan kesejahteraan masyarakat adalah pelaksanaan program-program keluarga berencana yang diamanahkan kepada BKKBN secara terencana, 
berkesinambungan, dan komprehensip untuk meningkatkan kesejahteraan masyarakat melalui kegiatan-kegiatan sosial yang diharapkan dapat mewujudkan tujuan dari program Keluarga Berencana. Program Kampung KB yang diteliti adalah program yang diimplementasi di Kelurahan Tampuna Kecamatan Bungi Kota Baubau, hal ini didasari oleh sejumlah keberhasilan program kampung KB yang diperolehnya.

Dalam teori implementasi kebijakan, maka program kampung KB dalam penelitian ini dapat diamati sebagai berikut:

\section{a. Sumber Daya}

Dalam memahami program kampong KB di Kelurahan Tampuna Kecamatan Bungi, didasari oleh ketersediaan Sumber daya, yang dalam kajian ini dilihat pada tiga sub indikator dalamnya yang digunakan dalam mendukung keberhasilan pelaksanan program Kampung KB, diantaranya yaitu: Sumber daya manusia, sumber daya anggaran, dan juga sumber daya fasilitas.

Sumberdaya manusia atau bisa juga disebut sebagai implementator dalam implementasi program Kampung KB Kelurahan Tampuan dinilai masih kurang dan tidak adanya pendekatan persuasif dari petugas Penyuluh Lapangan Keluarga Berencana (PLKB) ke masyarakat pada saat penyampaian materi dalam kegiatan sosialisasi. Selain itu, faktor budaya juga menjadi faktor yang turut memengaruhi kondisi sumber daya manusia, meskipun penyuluh berasal dari daerah tersebut tidak berarti mampu memberikan penyampaian materi dengan lebih efektif.

Sedangkan terkait dengan ketersedian sumberdaya finansial yaitu tidak mencukupinya anggaran yang telah disediakan, selain itu fasilitas dalam mendukung implementasi program Kampung KB Kelurahan Tampuna seperti sekretariat yang dapat digunakan masyarakat tidak tersedia sehingga masyarakat kesulitan jika ingin mengadakan pertemuan. Meskipun demikian, dari hasil penelitian ini menunjukkan bahwa dampak program terhadap kesejahteraan masyarakat cukup optimal.

Pada beberapa observasi dan wawancara yang dilakukan, sejumlah masyarakat merasa bahwa program kampung $\mathrm{KB}$ mampu menstimulus kesejahteraan masyarakat kelurahan tampuna. Hal ini terlihat dari berkembangnya usaha-usaha kecil masyarakat yang seiring dengan program kampung KB misalnya saja program pembangunan keluarga yang didalamnya terdapat pemberdayaan masyarakat kelurahan.

\section{b. Komunikasi}

Pada aspek komunikasi sebagai bagian dari implementasi program ditujukan pada proses untuk mengkoordinasi seluruh pihak terkait perkait kebijakan yang akan di terapkan. Selain itu. Komunikasi juga bermakna proses pelaksanaan setiap program yang dijalakan sebagai bagian dari program kampung $\mathrm{KB}$, yang dalam penelitian ini diantaranya adalah program kependudukan, program KB, Pembangunan Keluarga, Program KKBPK.

Aspke ini diukur, apabila tujuan serta sasaran dari suatu kebijakan tersebut tidak ada kejelasan maka kemungkinan 
akan adanya kesalahan dalam berbagai hal sehingga implementasi kebijakan tersebut pun tidak akan terlaksana dengan baik. Dari hasil penelitian ditemukan bahwa untuk komunikasi mengenai Program Kampung Keluarga Berencana Kelurahan Tampuna dalam meningkatkan kesejahteraan masyarakat di Kelurahan Tampuna Kecamatan Bungi terkait kondisi sosialisasinya bahwa pelaksanaan kegiatan sosialisasi berjalan dengan lancar dan telah sesuai dengan aturan dari Pemerintah Kota.

Hal ini juga didukung oleh pernyataan masyarakat yang diwawancarai pada penelitian ini bahwa hingga saat ini program kampung KB yang dilaksanakan memberikan efek pada kesejahteraan masyarakat pada umumnya. Namun, partisipasi dan kesadaran masyarakat masih kurang serta cenderung kurang semangat dalam mengikuti kegiatan sosialisasi tersebut. Adanya permasalahan internal juga menambah indikator dari sedikitnya masyarakat yang hadir, sehingga ketidak kompakan terbentuk dari dalam masyarakat. Selain itu, komunikasi antar para pelaksana atau implementator dalam program Kampung KB Kelurahan Tampuan Kecamatan Bungi masih belum berjalan dengan baik.

\section{c. Disposisi}

Dalam memahami proses implementasi selanjutnya adalah Disposisi. Memahami hal ini, bahwa disposisi terbentuk dari dua sub indikator yaitu sub indikator sikap dan juga sub indikator insentif yang di berikan oleh petugas dalam hal ini penyuluh lapangan dan kader. Sub indikator sikap yang bersifat positif maka akan terjadinya kegiatan yang memiliki koordinasi serta kesinambungan antara para implementor dengan masyarakat.

Berdasarkan hasil penelitian menunjukkan bahwa sikap yang diberikan oleh para penyuluh yaitu PLKB dan juga Kader didalam kegiatan program kampung KB di Kelurahan Tampuna Kecamatan Bungi Kota Baubau dari hasil wawancara yang dilakukan diperoleh data bahwa dari dengan adanya kampung KB ini nantinya akan mensejahterakan masyarakat Kelurahan Tampuna, dan diakui bahwa jika program tersebut berhasil maka hal itu menjadi suatu kebanggan bagi masyarakat dan kota baubau pada umumnya.

Disposisi PLKB dan Kader terkait komitmen dalam implementasi program Kampung KB Kelurahan Tampuna menunjukkan komitmen yang positif dan akan terus berkomitmen dengan memfasilitasi kebutuhan-kebutuhan yang berkaitan program Kampung KB tersebut. Selain itu, konsistensi dalam memajukan Kampung KB Kelurahan Tampuna menjadi program kerja berasama masyarakat yang dilakukan dengan meningkatkan pembinaan sumberdaya manusianya, tata lingkungannya dan kebersihannya agar masyarakat merasakan tujuan terbentuknya dari Kampung KB, khususnya untuk mencapai keluarga yang berkualitas serta sejahtera sesuai dengan 8 fungsi keluarga yaitu, fungsi agama, fungsi sosial budaya, fungsi cinta dan kasih sayang, fungsi perlindungan, fungsi reproduksi, fungsi pendidikan, fungsi ekonomi dan fungsi pelestarian lingkungan.

Selain itu, dalam hal peningkatan kesejahteraan masyarakat dari adanya Kampung KB Kelurahan Tampuna dirasakan dapat mendukung proses 
pemberdayaan masyarakat kelurahan Dimana dengan adanya program ini, kelompok masyarakat kelurahan tampuna menjadi mitra kerja pemerintah dapat meningkatkan kesejahteraan masyarakat secara umum. Hasil ini dapat dibuktikan dengan masyarakat kelurahan tampuna yang lebih produktif dalam menjalani suatu usaha, yang sebelumnya diberikan penguatan melalui penyuluhan dan pelatihan.

\section{d. Struktur Birokrasi}

Indikator implementasi selanjutnya adalah struktur birokrasi. Dalam memahami ini dapat dilihat dari pelaksanaan Standart Operasional Prosedur (SOP) dan pembagian tugas yang dilakukan oleh PLKB dan Kader.

Dalam penelitian yang dilakukan, dapat dijelasakana bahwa pelaksanaan SOP sendiri digunakan sebagai pedoman dalam pelaksanaan suatu program. SOP digunakan sebagai acuan langkah-langkah atau tahapan dari tindakan yang akan diambil selama proses pelaksanaan dari suatu kegiatan. Berdasarkan hasil dari penelitian yang telah dilakukan, SOP dari Kampung KB di Dusun Waung Desa Sonoageng Kecamatan Prambon Kabupaten Nganjuk sudah cukup baik, SOP yang digunakan yaitu berupa buku petunjuk teknis pelaksanaan Kampung $\mathrm{KB}$, mulai dari awal kegiatan hingga tahap akhir yaitu laporan dan juga evaluasi program semua mengikuti buku petunjuk teknis tersebut. Hanya saja perlu diakui bahwa terdapat kelompok masyarakat yang kurang aktif dalam menjalankan program.

Sedangkan dalam pembagian tugas, secara umum dapat digambarkan bahwa dalam hal ini telah berjalan dengan baik, meskipun tidak dapat dipungkiri bahwa masih terdapat beberapa kekurangan dalam pelaksananya di lapangan. Hal ini disebabkan oleh berbagai hal salah satunya adalah standar prosedur yang ditetapkan ternyata berbeda dengan kondisi dilapangan.

\section{Kesimpulan}

Berdasarkan penjelasan sebelumnya dalam penelitian ini, bahwa hampir semua indikator dari sudah berjalan dengan sangat baik terkait pelaksanaan program Kampung KB di Keluran Tampuna Kecamatan Bungi Kota Baubau khususnya pada Program Kependudukan, Program Kelurga Berencana, Pembangunan Keluarga, Program KKBPK dan Sektor lainnya berjalan dengan baik.

Sedangkan dalam memahami hal tersebut sebagai implementasi program kampung KB, dapat dijelaskan dalam empat indikator yang dinilai sudah berjalan dengan optimal. Hanya saja faktor sumberdaya manusia dan sarana prasarana yang masih kurang optimal, selain itu budaya masyarakat secara umum juga menjadi tantangan tersendiri bagi program kampung KB dari sisi program kependudukan.

\section{Daftar Pustaka}

Agustino, Leo. 2008. Dasar-dasar Kebijakan Publik. Bandung : Alfabeta.

Anisa, S.O. 2016. Efektifitas Kebijakan Kampung KB Terhadap Penerimaan Konsep Keluarga. Cilacap : Kertakarsa.

BKKBN. 2018. Integrasi Kampung KB Bersama Mitra Kerja. Jakarta : Direktorat Bina Lini Lapangan 
BKKBN. 2016. Pembentukan pengembangan Kampung Keluarga Berencana. Kota Baubau

Istiadi, A. (2017). Implementasi program kampung keluarga berencana (studi pada kelompok sasaran keluarga dengan remaja di dusun waung desa sonoageng kecamatan prambon kabupaten nganjuk). Publika, 5(4).

Kamus Besar Bahasa Indonesia. 2008

Nurjannah, S. N., \& Susanti, E. (2018). Implementasi Program Kampung Keluarga Berencana $(\mathrm{Kb})$ di Kabupaten Kuningan Tahun 2018 (Studi Kuantitatif Dan Kualitatif). Jurnal Ilmu Kesehatan Bhakti Husada: Health Sciences Journal, 9(2), 27-33.

Nurhafifah, Z. 2017. Implementasi Program Kampung KB Dalam Upaya Penanggulangan Kemiskinan. Bandar Lampung.

Nosa,B.A \& Sri,W. 2017. Implementasi Program Kampung Keluarga Berencana di Dusun Ambeng-ambeng Desa Ngingas Kecamatan Waru Kabupaten Sidoarjo.Jawa Timur.

Mardiyono. 2017. Pemberdayaan Keluarga Melalui Kampung KB Dalam Upaya Peningkatan Program KKBPK. Jawa Timur.

Moleong, Lexy J. 2013. Metodologi Penelitian Kualitatif. Bandung: PT Remaja Rosdakarya.

Pasolong, Harbani. 2011. Teori Administrasi Publik. Bandung: Alfabeta.

Sari, K. K., Irawan, B., \& Apriani, F. Implementasi Program Kampung Keluarga Berencana Gerbang Seribu Dalam Meningkatkan Kesejahteraan Masyarakat Di Kelurahan Sungai Dama Kota Samarinda.

Setiawati Elsa. 2017.Persepsi Masyarakat Terhadap Program Kampung Keluarga Berencana di Kelurahan Pantolan Boya Kecamatan Taweli. E- Journal GeoTadulako UNTAD.

Sugiyono. 2015. Metode Penelitian
Kuantitatif, Kualitatif dan $R \quad \mathcal{E} D$. Bandung: Alfabeta.

Wahab, Solichin Abdul. 2012. Analisis Kebijakan: dari Formulasi Penyusunan Model-Model Implementasi Kebijakan Publik. Jakarta : PT Bumi Aksara. 